\title{
Complejidad, Transdisciplinariedad y Transcomplejidad
}

\author{
Autora: María Esperanza Fonseca De Pineda \\ Universidad Fermín Toro, UFT \\ fonsecamaria975@gmail.com
}

Barinas, Venezuela

\begin{abstract}
Resumen
La educación actual tiene grandes obstáculos para avanzar. Y por eso nuestros esfuerzos por una mejor educación no prosperan. La educación del futuro debe considerar saberes que son normalmente ignorados en la actualidad. Diversos investigadores coinciden en señalar que el conocimiento es una construcción interactiva, lo que tiene importantes consecuencias al momento de analizar los procesos educativos; los profesionales de la docencia deben aprender a desaprender para que puedan asumir un nuevo pensamiento con fundamento en la actual visión del mundo postmoderno, cimentada sobre las bases de la complejidad, transdisciplinariedad y transcomplejidad, para que la enseñanza tome otra dirección, dirigida al trabajo desde el enfoque holístico para propiciar otras formas de pensamiento necesario para la transformación de las personas. Con este ensayo se pretende generar reflexiones profundas relacionadas con el proceso enseñanza-aprendizaje llevada a cabo por los docentes a través de la aplicación de la complejidad, transdisciplinariedad y transcomplejidad que responda a necesidades, aplicable a cualquier campo de conocimiento, disciplinas, teniendo como premisas el resguardo de la formación integral, moral y las buenas costumbres así como el valor del apego al núcleo familiar; con nuevas estrategias que permita abstraer, razonar, producir ideas, conceptos, emitir juicios y anticipar hechos innovadores.
\end{abstract}

Palabras clave: pensamiento; conocimiento; educación. 


\title{
Complexity, Transdisciplinarity and Transcomplexity
}

\begin{abstract}
Current education has great obstacles to advance. And that's why our efforts for a better education do not prosper. The education of the future must consider knowledge that is normally ignored at present. Several researchers agree that knowledge is an interactive construction, which has important consequences when analyzing educational processes; teaching professionals must learn to unlearn so that they can assume new thinking based on the current vision of the postmodern world, based on the bases of complexity, transdisciplinarity and transcomplexity, so that teaching takes another direction, directed to work from the holistic approach to promote other forms of thought necessary for the transformation of people. This essay aims to generate deep reflections related to the teaching-learning process carried out by teachers through the application of complexity, transdisciplinarity and transcomplexity that responds to needs, applicable to any field of knowledge, disciplines, having as premises the protection of integral, moral and good morals as well as the value of attachment to the family nucleus; with new strategies that allow to abstract, reason, produce ideas, concepts, make judgments and anticipate innovative facts.
\end{abstract}

Keywords: thinking; knowledge; education. 


\section{Introducción}

Los debates en torno a lo relacionado con los principios y valores, tanto éticos como morales, llevan a señalar que se han perdido los mismos, que se cambiaron, por ello precisamos un mundo de paradigmas que contiene reglas y normas, que hacen constituir o definir límites para conocernos a nosotros mismos, en el entorno, permitiéndonos precisar las realidades que tenemos. Tal punto de vista se torna complejo en los espacios destinados para la educación por el cúmulo de conocimientos, que depende netamente de la actitud de los docentes al incidir en el comportamiento de los educandos, quienes, bajo los paradigmas adquiridos, construirán sus propias riendas de vida.

La perspectiva lleva a que varíe la percepción de enseñar en los profesionales de la docencia, por su esencia endógena, que en sí, genera su cultura y demás patrones, por lo que deben asumir un nuevo pensamiento con fundamento en la actual visión del mundo postmoderno, cimentada sobre las bases de la complejidad, transdisciplinariedad y transcomplejidad, para que la enseñanza tome otra dirección, dirigida al trabajo desde un enfoque holístico para propiciar otras formas de pensamiento necesario para la transformación de las personas.

Desde mi óptica, debe ser así, debido a que siempre vivimos comunicando conocimientos e ideas, en función del manejo de la información, aunado al conjunto de experiencias adquiridas. En este sentido, Aragoza (2010a), señala que los individuos "son formados desde todos los tiempos por los demás a partir de sus principios éticos" (pág. 87). Por lo tanto, la forma de hacer llegar lo que se ha de conocer conforme a cada ser humano, así como de su grupo social; de esta manera ha de trascender la enseñanza, por ejemplo, en los estudiantes, con miras a la desconstrucción de los diferentes pensamientos para llegar a una nueva construcción de estos, transfiriendo patrones de conducta distintos y actuación positiva. 


\section{Complejidad, Transdisciplinariedad y Transcomplejidad}

Alcanzar el cambio paradigmático en los docentes tiene que sustentarse en la reconstrucción transdisciplinaria, pero el ejercicio del desempeño docente sigue manteniendo una aplicación integradora, aun cuando lo demanda el sistema educativo formal. Los saberes no se trasmiten dentro de la relación holística que hay en ellos, es por ello que se presentan fallas en el proceso de enseñanza-aprendizaje. En torno a lo último reflejado, Aragoza (2010b), señala:

Durante la praxis educativa, en los niveles de la educación media, considero no se incluyen procesos que configuren la humanidad entre los que integran el contexto, al verse que entre los mismos profesores no se evidencia la integración con la participación, cooperación, intervención e igualdad, ...obviando los fundamentos curriculares. La formación no se propicia desde la construcción y reconstrucción de la vida, para la vida... (pág. 135).

En el mundo educativo de los liceos, los docentes agotan su misión formadora integral holística, y se inclinan solo en el desarrollo de contenidos, la mayoría, ajenos a la realidad. El ejercicio docente aún se mantiene alejado de su función holística, en tanto se ha convertido en una máquina de reproducción de contenidos, sin un espacio real a la crítica, a la reflexión, al análisis de nuevas experiencias y a la formación de nuevos pensamientos.

En Venezuela, el Currículo Nacional se considera un tema de importancia en la formación integral del individuo. Por lo que resulta arduo, plantearse una teoría educativa transformadora, acorde con las necesidades transdisciplinarias y transcomplejas, teniendo como premisas el resguardo de la salud sexual, la moral, la práctica y las buenas costumbres, así como el valor del apego al núcleo familiar; proponiendo además nuevas estrategias que permitan abrir espacios a la crítica y a la innovación del pensamiento.

La escuela se aparta el contexto social del individuo, al no formar al 
joven por y para la vida. Las instituciones educativas, deben orientarse a la construcción de una nueva praxis pedagógica, fundada en la realidad social del individuo, y en constante renovación acorde con los cambios sociales de su entorno. Al respecto, Peña (2018a), plantea:

La formación y actualización constante del docente, es considerada como una herramienta que busca la instrucción conforme en el desarrollo del estudiante; este tipo de actualización, se promueve mediante dos vías, una se da en base a los colectivos institucionales, diseñados de forma directa y participativa integrando todos los perfiles profesionales al uso y aplicación de todas las mecánicas estructurales de un programa pedagógico; la otra es el docente investigador, propagador de ideas que satisfagan las necesidades cognitivas y formativas, así como las actitudinales, todas ellas inherentes al perfil idóneo del docente (pág. 217).

Se destaca, la formación del docente es fundamental en la enseñanza de los estudiantes, razón por cual incide en los cambios de actitudes de los mismos. Es por ello, la actualización permanente del educador obedece a la participación en colectivos de capacitación en función de fortalecer su rol como investigador, orientador, mediador de aprendizajes, innovador y humanista en el desarrollo integral de los alumnos. En consecuencia, la imagen de la sociedad que se construye, desde el escenario educativo, está desvinculada a la realidad social.

En este sentido, la complejidad, según Morin (2001), es como: "[...] un tejido de constituyentes heterogéneos inseparablemente asociados: presenta la paradoja de lo uno y lo múltiple. Es, efectivamente, el tejido de eventos, acciones, interacciones, retroacciones, determinaciones, azares, que constituyen nuestro mundo fenoménico. [...]" (pág. 32). Esto refiere, la complejidad ofrece el entendimiento de fenómenos, permitiendo dar precisión a la relación complejidad-realidad.

De allí, Peña (2018b), expone que "la teoría de la complejidad capta la 
realidad como sistema complejo, en sus diversas conexiones, mediaciones y condicionamientos. Por eso no establece relaciones antitéticas entre orden y caos, incertidumbre y certidumbre, entre las partes y el todo" (pág. 222). La autora refleja que la teoría de la complejidad realiza el abordaje de las entidades complejas con los numerosos enlaces, negociaciones, armonización e interconexiones del caos y la incertidumbre.

En los actuales momentos de postmodernidad, donde predominan los cambios de ideologías y un pensamiento más complejo, resulta inminente un replanteo en los sistemas educativos, apuntando hacia la búsqueda de nuevas verdades, que como se interpreta en Balza (2011a), conlleven a una nueva visión transdiciplinaria acore con los nuevos tiempos y con una nueva moral. Al respecto, Morin, citado por Carmona (2004), refiere "la realidad es compleja...y a través de la transdisciplinariedad nos acercaremos a ella" (pág. 4). Esto refiere, la realidad, en su esencia, está determinad por una vertiente compleja y es por medio de la transdisciplinariedad que se puede lograr el acercamiento más próximo hacia ella.

Por lo tanto, se hace un llamado a exponer nuevas vertientes que funcionen como alternativas innovadoras y creativas que cambie la manera de actuar del docente para que se oriente hacia la construcción rigurosa de la conciencia moral en los estudiantes, a través del intercambio efectivo de saberes culturales y morales, tal como lo permite ver Muaje (2010a), quien señala, que "el docente establezca en las diversas interrelaciones con las personas que forma la posibilidad de cambios conscientes de principios que afiancen y lleven hacia actuaciones positivas" (pág. 63), para que de paso a la desconstrucción del pensamiento actual, para propiciar otro que dé pie a otra actitud de transferir los principios de la educación.

Lo que implicaría desconstruir el pensamiento actual para darle cabida a una nueva forma de generar ideas, que solvente problemas a través de la transdisciplinariedad, y fortalezca los procesos a partir de un enfoque más 
holístico. Esto demanda entonces, un docente que erradique viejas prácticas, presentes en su desempeño laboral, y funde un nuevo pensamiento de orden superior que se corresponda con las demandas del momento, donde la autopoiesis sea la principal condición de trabajo. Por tanto, la comunicación educativa ha de ser de calidad, retando los procesos desde una visión compartida, apostando hacia la autoestima y autoconfianza, tanto del docente como del educando.

El docente actuará dando respuesta a las exigencias gubernamentales, institucionales y sociales, cuidando de la seguridad biopsicosocial de los educandos, y especialmente de los adolescentes, para generar confianza, y orientarlos hacia el éxito, tomando el tema de la sexualidad, por ejemplo, como premisa para el desarrollo del ser, estableciendo así, una sinergia que incrementa las responsabilidades en el desempeño del ejercicio de funciones docentes.

Éste ha de generar modelos de gestión transdisciplinario para que se propicien las inter-funciones, de donde emerjan las soluciones viables y operativas, considerando, desde mi punto de vista, una transversalidad que funcione con unión disciplinaria para que, desde el epicentro de su totalidad, se logren los cambios con base al conocimiento, en la redefinición de la enseñanza de educación sexual en adolescentes. Interpretando a Balza, (2011b), se tiene que partir del análisis integral consciente de todo cuanto comprenden las realidades, en sus múltiples interacciones, para que se avance hacia niveles profundos del significado en la resignificación de una verdadera educación significativa.

La concepción del docente se dirigirá hacia el desarrollo integral del individuo, en un desempeño competente, con nuevos esquemas mentales, tomando en cuenta la visión hologramática, desde la hermeneusis de la transcomplejidad que plantea Balza (2011c), en un nuevo modo de repensar la enseñanza con cognición de orden superior, a partir de la logicidad 
multidimensional para su reconfiguración, lo que lleva consigo a establecer diversas formas de transcender el conocimiento en correspondencia con la sistematización reflexiva tomando en cuenta los preceptos teórico y metodológicos, desde dicho enfoque hologramático como como elemento emergentes desde las realidades de los contextos de forma global.

Se contemplará la articulación de una enseñanza dialógica para la construcción en la globalidad, considerando el conocimiento, en correspondencia absoluta con las interconexiones que vibran a ritmo de lo que sucede, qué lo genera, sus causas y consecuencias, bajo la propuesta heurística en todos los planos del saber, centrada en la reflexión discusiva en la interconexión de transformaciones ideológicas profundas, sensatas y reflexivas, como significado para la promoción del cambio individual, repercutiendo sobre lo social, con la visión centrada en la comprensión epistemológica de abordar los significados necesarios para la renovación de la enseñanza de la educación, integrando esfuerzos, minimizar la fragmentación del saber humano, como partes de un todo, que debe estar relacionado entre sí, en comunicación constante.

En este sentido, conseguir un verdadero cambio en la educación, según Muaje (2010b), implica "repensar los existentes haceres, desde la heurística de una nueva construcción mental para dar paso a un nuevo modo de pensar" (pág. 92). Consiste en que los docentes se involucren en un nuevo paradigma innovador, en cuanto a procesos de integración cognitiva.

El nuevo pensamiento docente debe estar enmarcado dentro de un espacio intelectual crítico y reflexivo a partir del cual se pueda generar importantes transformaciones en cada individuo, a partir de sus experiencias. Es allí donde se fundamenta el gran paradigma humanista con tendencias hacia el bienestar biopsicosocial personal, que incida positivamente en su comunidad. 


\section{Reflexiones Finales}

Los docentes juegan un papel fundamental en la construcción del esquema del desarrollo integral de los adolescentes, siendo así, responsables de conducir vidas. En otras palabras, se destaca ser un auténtico profesional docente; conduciendo a afianzar un pensamiento más trascendente, interactivo y reflexivo. Además, de poseer una dimensión social que se ha de afincar sobre sus principios éticos como parte del compromiso responsable que tiene en la reforma educativa, para revalorización del individuo. El tratamiento por seguir se hará sobre las bases de la complejidad y transdisciplinariedad, enfocadas o cimentada en la integridad humana.

La práctica educativa de orientarse a generar cambios drásticos que permita el resurgimiento de nuevas prácticas de enseñanza, sin restricciones, donde la influencia que ejerzan los docentes sobre los estudiantes sea mayor $\mathrm{y}$ desencadene un verdadero progreso evolutivo como seres humanos. Involucra repensar la manera de hacer las transferencias de los conocimientos replanteando modelos de enseñanza. El objetivo entonces radica en fortalecer los principios humanistas de la enseñanza para reforzar sus propios sentimientos que permitirán, con el firme propósito que se dignifique al individuo como sujeto que piensa, razona y siente.

La complejidad se unirá al diseño y ejecución de la práctica docente, desde el punto de vista pedagógica, permitiendo la educación humanista, concertando el conocimiento enseñado con lo que se ha de aprender en actitud reflexiva y critica, sin perder la sensibilidad humana, en relaciones de redimensionar el pensamiento, creando conciencia de orden superior para la conducción y manejo de la propia vida, enfrentando con dialéctica el pensamiento para que vaya evolucionado constantemente, en la desconstrucción consecuente de lo pensado para darle solución a los problemas que se vayan suscitando en el proceso de enseñanza y aprendizaje. 
Por lo tanto, la complejidad, transdisciplinariedad y transcomplejidad como procesos que enmarcan procedimientos, acciones, vías, formas y medios de actuación que complementan el proceso enseñanza-aprendizaje, con una visión yuxtapuesta que fortalezca los conocimientos, a través de conexiones entre la cultura escolar y la social, trascendiendo los espacios educativos espacial, temporal, temático y vital del pensamiento.

\section{Referencias}

Aragoza, E. (2010a,b). Los valores en el desarrollo de competencias en educadores. México: Distribuciones Fontamara, S.A.

Balza, A. (2011a,b,c). Complejidad, transdisciplinariedad y transcomplejidad. Los caminos de la nueva ciencia. Venezuela: Asociación de Profesores de la Universidad Nacional Experimental Simón Rodriguez, APUNESR.

Carmona, M. (2004). Transdisciplinariedad: Una propuesta para la Educación Superior en Venezuela. Revista Pedagógica, 25(73), 5970. Recuperado de:

http://www.scielo.org.ve/scielo.php?script=sci arttext\&pid=S079897922004000200007\&lng=es\&tlng=

Morin, E. (2001). Introducción al Pensamiento Complejo. Barcelona: Gedisa.

Muaje, G. (2010a,b). Pensamiento educativo. Buenos Aires: Editorial Ediciones Nueva Visión.

Peña, J. (2018a,b). Transformación del Docente Desde el Pensamiento Complejo. Revista Scientific, 3(7), 211-230. Recuperado de: https://doi.org/10.29394/Scientific.issn.2542-2987.2018.3.7.11.211-230 


\section{María Esperanza Fonseca de Pineda \\ e-mail: fonsecamaria975@gmail.com}

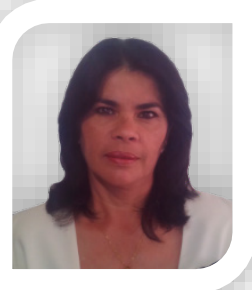

Nacida en Guanare, estado Portuguesa, Venezuela.

Casada y de profesión docente. Realicé estudios de primaria en el Grupo Escolar estado Guárico en el estado Barinas, obtuve el título de bachiller en el Instituto educativo "Venezuela" en el estado Barinas, culminé los estudios universitarios de pregrado en la Universidad Pedagógica Experimental "Libertador" (IMPM) en el año 2009 obteniendo el título de Profesora en Especialidad Educación Integral, realicé estudios de postgrado en la misma Universidad en el año 2011, obteniendo el título de Especialista en Educación Comunitaria. Actualmente me desempeño como orientadora en el departamento de Bienestar estudiantil del Liceo Bolivariano "Trina Briceño de Segovia".

El contenido de este manuscrito se difunde bajo una Licencia de Creative Commons ReconocimientoNoComercial-Compartirlgual 4.0 Internacional 